\title{
Mutational analysis of the insulin-like growth factor 1 receptor tyrosine kinase domain in non-small cell lung cancer patients
}

\author{
KATHY GATELY ${ }^{1}$, LYDIA FORDE ${ }^{1}$, STEPHEN GRAY $^{1}$, DEREK MORRIS ${ }^{2}$, AIDAN CORVIN $^{3}$, \\ PRERNA TEWARI ${ }^{4}$ and KENNETH O'BYRNE ${ }^{1,5}$
}

\author{
${ }^{1}$ Thoracic Oncology Research Group, ${ }^{2}$ Neuropsychiatric Genetics Research Group, Institute of Molecular Medicine, \\ Trinity College Dublin, St. James's Hospital, Dublin; ${ }^{3}$ Discipline of Biochemistry, National University of Ireland, Galway; \\ ${ }^{4}$ Molecular Pathology Research Group, Trinity College, Coombe Womens and Infants University Hospital, Dublin, \\ Republic of Ireland; ${ }^{5}$ Medical Oncology, Princess Alexandra Hospital, Queensland University \\ of Technology, Translational Research Institute, Brisbane, Queensland, Australia
}

Received March 17, 2015; Accepted April 2, 2015

DOI: $10.3892 / \mathrm{mco} .2015 .580$

\begin{abstract}
The insulin-like growth factor 1 receptor (IGF1R) pathway plays an important role in the pathogenesis of non-small cell lung cancer (NSCLC) and also provides a mechanism of resistance to targeted therapies. IGF1R is therefore an ideal therapeutic target and several inhibitors have entered clinical trials. However, thus far the response to these inhibitors has been poor, highlighting the importance of predictive biomarkers to identify patient cohorts who will benefit from these targeted agents. It is well-documented that mutations and/or deletions in the epidermal growth factor receptor $(E G F R)$ tyrosine kinase (TK) domain predict sensitivity of NSCLC patients to EGFR TK inhibitors. Single-nucleotide polymorphisms (SNPs) in the IGF pathway have been associated with disease, including breast and prostate cancer. The aim of the present study was to elucidate whether the IGFIR TK domain harbours SNPs, somatic mutations or deletions in NSCLC patients and correlates the mutation status to patient clinicopathological data and prognosis. Initially 100 NSCLC patients were screened for mutations/deletions in the IGFIR TK domain (exons 16-21) by sequencing analysis. Following the identification of SNP rs2229765, a further 98 NSCLC patients and 866 healthy disease-free control patients were genotyped using an SNP assay. The synonymous SNP (rs2229765) was the only aberrant base change identified in the IGFIR TK domain of 100 NSCLC patients initially analysed. SNP rs2229765 was detected in exon 16 and was found to have no significant association between IGF1R expression and survival. The GA genotype was identified in 53.5 and $49.4 \%$ of NSCLC patients and control individuals, respectively. No
\end{abstract}

Correspondence to: Dr Kathy Gately, Thoracic Oncology Research Group, Institute of Molecular Medicine, Trinity College Dublin, St. James's Hospital, James's Street, Dublin (D8), Republic of Ireland

E-mail:kgately@stjames.ie

Key words: insulin-like growth factor 1 receptor, single-nucleotide polymorphism, non-small cell lung cancer, targeted therapy significant difference was found in the genotype $(\mathrm{P}=0.5487)$ or allele $(\mathrm{P}=0.9082)$ frequencies between the case and control group. The present findings indicate that in contrast to the EGFR TK domain, the IGF1R TK domain is not frequently mutated in NSCLC patients. The synonymous SNP (rs2229765) had no significant association between IGF1R expression and survival in the cohort of NSCLC patients.

\section{Introduction}

The role of the insulin-like growth factor 1 receptor (IGF1R) in the pathogenesis of malignant epithelial tumours, including non-small cell lung cancer (NSCLC), has been well-characterised (1-5). Activation of this receptor pathway promotes tumour growth by inhibition of apoptosis, transformation, metastasis and induction of angiogenesis through vascular endothelial growth factor (6-10).

IGF1R is frequently overexpressed in NSCLC patients, however, there is controversy over its significance as a prognostic marker. Certain studies have shown no correlation between high IGF1R expression and patient survival $(3,4)$; conversely, other studies have demonstrated that high IGF1R expression was associated with nodal metastasis, recurrence and a significantly poorer overall survival (OS) rate in NSCLC patients $(11,12)$. A recent meta-analysis suggests IGF1R positive expression as an adverse factor for disease-free survival (DFS) in NSCLC patients and reports the correlation to smoking status and tumour size, but there was no significant association between IGF1R expression and OS on univariate or multivariate analysis (13). Ludovini et al (14) reported that high co-expression of IGF1R and epidermal growth factor receptor (EGFR) is associated with a shorter DFS in resected NSCLC patients and a trend towards a poorer OS. We have previously shown that high co-expression of EGFR and IGF1R correlates with poor patient prognosis in resected NSCLC (15).

Following the success of other targeted therapies, such as the EGFR inhibitors, IGF1R also emerged as an attractive therapeutic target. Although the results from early clinical trials targeting IGF1R showed certain promise, larger randomized phase III trials have not shown a clear clinical benefit of 
targeting this pathway in combination with chemotherapy (16). The results of these trials and others involving targeted agents have demonstrated the importance of identifying predictive biomarkers to select the appropriate patient population who will benefit from treatment.

Somatic mutations in the kinase domain of a receptor can cause the cell to become highly dependent on the constitutively active receptor signalling pathway. These aberrations can also cause conformational changes that can impact on the binding capabilities of a therapeutic agent targeting this region (17-22). As many as 2,412 single-nucleotide polymorphisms (SNPs) have been identified in IGFIR and several have been associated with a cancer risk (22-26). A common polymorphism of the IGFIR gene (G1013A) has been shown to modify the risk of obesity for esophageal adenocarcinoma and, in combination with a polymorphism in $I G F 2 R(\mathrm{G} 1619 \mathrm{~A})$, is an independent prognostic factor in advanced NSCLC (27-29). A previous study has shown that the IGF1 pathway polymorphisms are potential predictive/prognostic molecular markers for cetuximab efficacy in wild-type KRAS colorectal cancer patients (30). These polymorphisms may activate crosstalk between the IGF1R and EGFR signalling pathways. A study by Deming et al (31) on genetic variation in patients with breast cancer found that SNP rs951715 within the IGF1R gene was associated with breast cancer survival in postmenopausal women. Another polymorphism, SNP rs2229765, appears to be a silent mutation with no correlation to survival rate in breast cancer patients and thus far has no association with any epidemiological traits. In a retrospective study of 304 NSCLC patients who underwent curative pulmonary resection, 1 silent mutation in exon 16 and 3 intronic mutations were detected within the IGF1R gene but did not correlate to IGF1R protein expression (32).

Identifying functional polymorphisms in the IGF1R pathway could be used to select patients who may benefit from IGF1R-targeted agents. Thus far, there have been few reports of SNPs or somatic mutations in the IGFIR tyrosine kinase (TK) domain. Therefore, the aim of the present study was to screen NSCLC patients, who had undergone lung tumour resection surgery, for gene aberrations in the IGF1R TK domain.

\section{Materials and methods}

Subjects. This is a retrospective study in which a database of all the patients who underwent curative-intent surgical resection of a primary tumour at St. James's Hospital, Dublin (Republic of Ireland) between February 2001 and February 2005, was analysed. A cohort of 198 stage I-III NSCLC patients, staged according to the International System of Staging for Lung Cancer (33), was randomly selected from the database. Information on baseline demographics, clinicopathological characteristics and surgical approach was collected following a review of clinical notes and histopathology reports. Outcome data, including peri-operative mortality and long-term survival, were updated prospectively. Patient characteristics are detailed in Table I. The study was approved by the St. James's Hospital Ethics Committee. Controls $(n=866)$ were ascertained with written informed consent from the Trinity Biobank and represented blood donors from the Irish Blood Transfusion Service recruited in the Republic of Ireland. Individuals taking regular prescribed medication are excluded from blood donation in the Republic of Ireland and donors are not financially remunerated.

DNA extraction. DNA was extracted from $3 \times 10-\mu \mathrm{m}$ formalin-fixed paraffin-embedded sections from NSCLC patients and prepared using the QIAamp ${ }^{\circledR}$ DNA kit. DNA was extracted from control blood samples using the Gentra Autopure system (Qiagen, Hilden, Germany).

PCR amplification of exons 16-20. The primer sequences used for the PCR reactions are outlined in Table II. The following PCR conditions were used: 1X GoTaq ${ }^{\circledR}$ Green Master mix (Promega Corp., Madison, WI, USA), $5 \mu \mathrm{M}$ of forward and reverse primers and $100 \mathrm{ng}$ of DNA made up to a volume of $50 \mu \mathrm{l}$ with $\mathrm{dH}_{2} \mathrm{O}$. A pre-PCR heat step of $94^{\circ} \mathrm{C}$ for $5 \mathrm{~min}$ was carried out to activate the enzyme and the DNA was amplified for 35 cycles at $94^{\circ} \mathrm{C}(1 \mathrm{~min}), 56^{\circ} \mathrm{C}(1 \mathrm{~min})$ and $72^{\circ} \mathrm{C}(1 \mathrm{~min})$, and at $72^{\circ} \mathrm{C}(10 \mathrm{~min})$ after the last cycle. A portion of the PCR product was electrophoresed on a $1.4 \%$ agarose gel to verify product integrity. PCR products were purified using the Qiagen QIAquick PCR purification kit. The DNA was measured using the NanoDrop 1000 spectrophotometer.

Sanger sequencing of PCR products. Sanger sequencing reactions were set up as follows: $2 \mu 1$ BigDye ${ }^{\circledR}$ Terminator mix v3.1, 50 ng DNA, $5 \mu \mathrm{M}$ forward or reverse primers and $2 \mu \mathrm{l}$ sequencing buffer, diluted to $20 \mu \mathrm{l}$ with water. A positive control was also set up to ensure the efficiency of the sequencing reaction $\left(1 \mu \mathrm{l} \mathrm{pGem}, 2 \mu 1 \mathrm{M} 13\right.$ primer, $2 \mu \mathrm{l} \mathrm{BigDye}^{\circledR}$ Terminator mix v3.1 and $2 \mu 1$ sequencing buffer). The pGem and BigDye ${ }^{\circledR}$ Terminator mix v3.1 were sourced from Applied Biosystems (Warrington, UK). Sequencing was performed on a 3130xl genetic analyser (Applied Biosystems, Foster City, CA, USA) and sequencing files were analysed using the BioEdit v 7.0.8 (Ibis Biosciences, Carlsbad, CA, USA).

SNP genotyping assay. A TaqMan ${ }^{\circledR}$ SNP genotyping assay (Applied Biosystems) that detected the SNP at codon $3179 \mathrm{~A}>\mathrm{G}$ (rs2229765) in exon 16 of the TK domain by quantitive PCR was also used to screen patients. TaqMan ${ }^{\circledR}$ SNP Genotyping Assay 5' nuclease technology uses two allele-specific TaqMan ${ }^{\circledR}$ MGB probes and a PCR primer pair to detect the specific SNP target. The probes and primers uniquely align with the genome, enabling TaqMan ${ }^{\circledR}$ genotyping technology to provide unmatched specificity. Genotype data for rs2229765 was generated on the control samples using the Genome-Wide Human SNP Array 6.0 (Affymetrix, Inc., Santa Clara, CA, USA) (34).

Immunohistochemistry. IGF1R immunohistochemical analysis was performed on 4- $\mu \mathrm{m}$ slides cut from 22 tissue microarrays and mounted on Superfrost Plus glass slides (Thermo Fisher Scientific, Inc., Waltham, MA, USA). The entire staining procedure was performed on an automated immunohistochemistry device [BenchMark XT; Ventana Medical Systems, Inc. (VMS), Tucson, AZ, USA] following the manufacturer's instructions. In brief, slides were deparaffinized on the thermopads using the Ez Prep reagent (950-102; VMS). For epitope recovery, the standard CC1 buffer, a citric-acid-based antigen retrieval solution, was used (950-102; VMS). All the 
Table I. Patient characteristics.

\begin{tabular}{lcc}
\hline Characteristics & Cases, $\mathrm{n}$ & Controls, $\mathrm{n}$ \\
\hline Total & 198 & 866 \\
Gender & & \\
Male & 125 & 296 \\
Female & 73 & 570 \\
Smoking history & & \\
Former & 130 & ND \\
Current & 57 & ND \\
Never & 11 & ND \\
Histology & & \\
SCC & 94 & ND \\
ADC & 84 & ND \\
Other & 20 & ND \\
Age, years & & \\
$<50$ & 28 & 698 \\
$>50$ & 170 & 168 \\
\hline
\end{tabular}

ND, not determined.

Table II. Primer sequences used for amplification of $I G F 1 R$ RTK 1-6.

\begin{tabular}{ll}
\hline Exon & \multicolumn{1}{c}{ Primer sequence $\left(5^{\prime}-3^{\prime}\right)$} \\
\hline RTK1 & F: GGCTTGTTTCTGTACCTGCT \\
& R: AGCCAAGAACATACTGGGAG \\
FTK2 ACAACACAGGCATCAGCAAG \\
R: GACACAGCATTTCCTTGCAG \\
FTK3 CTCGAAAGAAATTGGCATGG \\
R: TCTCCAGGGGCAGACTAATG \\
RTK4 & F: CTGCTCCAGCGTGTGACTCT \\
& R:GAGCTAAAGCTGGCAACGGG \\
RTK5 & F: CTGCTCGGGATGTAAGAAGT \\
& R: CTCCTAATCTCCTGTGACCC \\
RTK6 & F: CGTACGAGGTAAACAGGAG \\
& R: AGCTTGTTCTCCTCGCTGTA
\end{tabular}

$I G F 1 R$, insulin-like growth factor 1 receptor; RTK, receptor tyrosine kinase; F, forward; R, reverse.

subsequent washing and blocking steps followed standard protocols. Slides were incubated with the prediluted primary antibody (monoclonal rabbit anti-IGF1R, clone G11; VMS) for $16 \mathrm{~min}$ at $37^{\circ} \mathrm{C}$. Negative controls included identically processed slides in which the primary antibody was replaced by accordingly diluted non-immune rabbit IgG (Abcam, Cambridge, UK; 27478). Positive controls included identically treated paraffin slides of a H322M xenograft, an IGF1R-overexpressing NSCLC cell line. Detection of primary antibody binding was performed using the ultraView Universal DAB Detection kit (760-091; VMS). After the diaminobenzidine (DAB) reaction was developed, slides were counterstained
Table III. Characteristics for the SNP rs2229765, evaluated in the present study.

\begin{tabular}{lc}
\hline Characteristics & SNP \\
\hline Gene name & $I G F 1 R$ \\
Alleles, major $>$ minor & $\mathrm{G}>\mathrm{A}$ \\
SNP reference ID & rs 2229765 \\
Position in gene & Exon 16 \\
Codon & Glu1013Glu
\end{tabular}

Polymorphism data on SNP rs2229765 was retrieved from the NCBI SNP reference database. SNP, single-nucleotide polymorphism.

Table IV. Genotypic and allelic frequency of SNP rs2229765 in NSCLC and control patients.

\begin{tabular}{lccc}
\hline Frequency & $\begin{array}{c}\text { NSCLC patients } \\
(\mathrm{n}=198), \mathrm{n}(\%)\end{array}$ & $\begin{array}{c}\text { Control patients } \\
(\mathrm{n}=866), \mathrm{n}(\%)\end{array}$ & P-value \\
\hline Genotype & & & \\
AA & $35(17.7)$ & $175(20.2)$ & 0.5487 \\
GA & $106(53.5)$ & $428(49.4)$ & \\
GG & $57(28.8)$ & $263(30.3)$ & \\
Allele & & & \\
A & $176(44.4)$ & $778(44.9)$ & 0.9082 \\
G & $220(55.5)$ & $954(55.0)$ & \\
\hline
\end{tabular}

SNP, single-nucleotide polymorphisms; NSCLC, non-small cell lung cancer.

with haematoxylin II (760-500; VMS), dehydrated in a serial dilution of ethanol, transferred in xylene and mounted with Eukitt (O. Kindler GmbH, Freiburg im Breisgau, Germany).

Statistical analysis. The software package SPSS v16.0 (SPSS Inc., Chicago, IL, USA) was used to perform the statistical analysis. $\chi^{2}$ test, Cox regression analysis, Kaplan-Meier analysis and the log-rank test were used to illustrate the significance of various clinical characteristics. Assumption of the proportional hazard was tested for all covariates. $\mathrm{P}<0.05$ was considered to indicate a statistically significant difference.

\section{Results}

Initially, 100 NSCLC patients were screened for the presence of mutations, deletions or SNPs in exons 16-20 of the TK domain of IGF1R. The polymorphism (rs2229765) located on exon 16 of the IGFIR gene (GenBank accession NM_000875), consisting of a $\mathrm{G}$ to $\mathrm{A}$ transition at nucleotide 3174 but not leading to an amino acid change (Glu->Glu) at position 1043 (E1043E) (GenBank accession NP_000876), was identified (Table III). No other mutations, deletions or SNPs were found in the TK domain. A further 98 NSCLC patients were screened for the presence of the same SNP (rs2229765) and compared to the control disease-free individuals $(\mathrm{n}=866)$. The control patient DNA used came from 
A

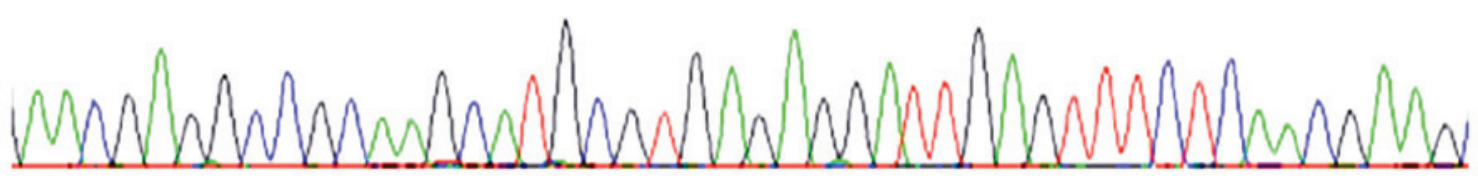

B

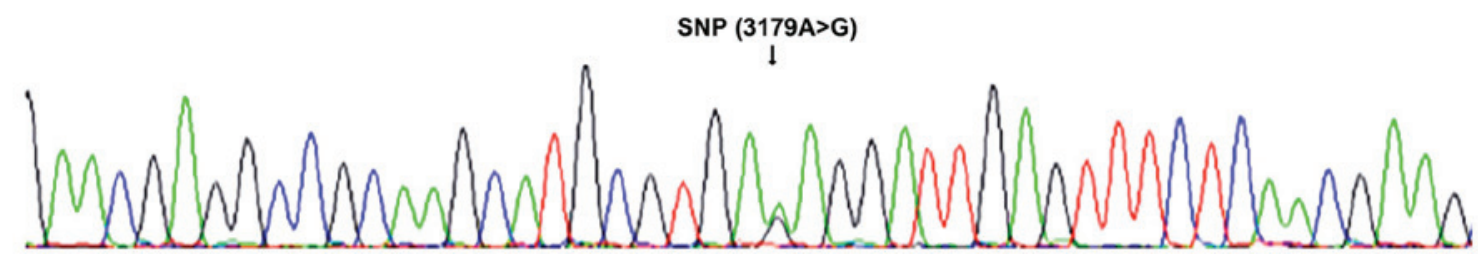

Figure 1. Forward sequence traces from a non-small cell lung cancer (NSCLC) patient with (A) no single-nucleotide polymorphism (SNP) (homozygous G/G) and (B) a heterozygous SNP (SNP 3179A $>$ G) in exon 16.

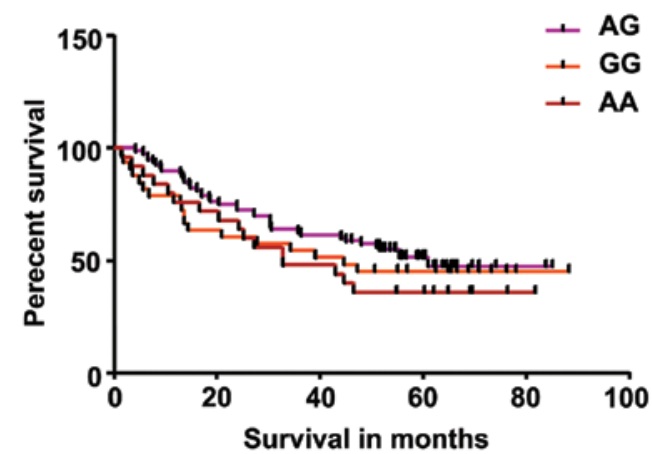

Figure 2. Kaplan-Meier plot of genotype distribution of SNP rs2229765 in non-small cell lung cancer (NSCLC) patients (log rank test $\mathrm{P}=0.3564)$.

A

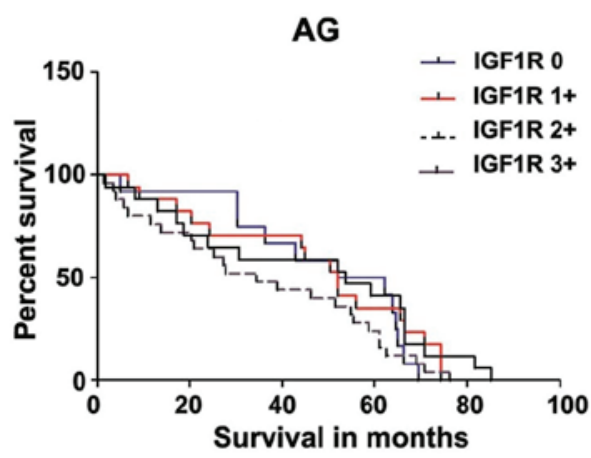

B

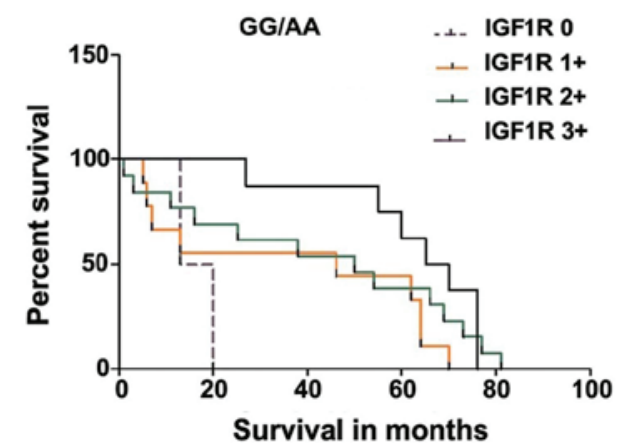

Figure 3. Kaplan-Meier plot correlating insulin-like growth factor 1 receptor (IGF1R) expression to genotype distribution of SNP rs2229765 in non-small cell lung cancer (NSCLC) patients. (A) Heterozygous A/G, (B) homozygous dominant $\mathrm{GG}$ and homozygous recessive AA. Log rank test (A) $\mathrm{P}=0.3005$ and (B) $\mathrm{P}=0.1164$. the Trinity Biobank in the Institute of Molecular Medicine, Trinity College Dublin. These results where subsequently correlated to patient survival/pathological data. Example sequence traces from a homozygous $\mathrm{G} / \mathrm{G}$ patient and a heterozygous $\mathrm{A} / \mathrm{G}$ patient are shown in Fig. 1A and B, respectively.

The heterozygous GA genotype was found in 53.5 and $49.4 \%$ of NSCLC patients and controls, respectively (Table IV). The dominant GG genotype was identified in 28.8 and $30.3 \%$ of NSCLC patients and control individuals, respectively, while the recessive AA genotype was found in 17.7 and $20.2 \%$ of NSCLC patients and control individuals, respectively. No significant difference was found in the genotype $(\mathrm{P}=0.5487)$ frequency between cases and controls. The A allele was identified in 44.4 and $44.9 \%$ of NSCLC patients and control individuals, respectively, while the $\mathrm{G}$ allele was identified in 55.5 and 55\% of NSCLC patients and control individuals, respectively. No significant difference was identified in the allelic $(\mathrm{P}=0.9082)$ frequency.

From the overall patient and control cohorts, patients $>70$ years were excluded as there were no matched controls available for this age group. Age and gender matching ensures that any difference between cases and controls is disease-related. The genotypic and allelic frequencies were subsequently examined in 95 NSCLC patients and 95 age- and gender-matched control individuals. When patients were age- and gender-matched the GA genotype was identified in 56.8 and $48.4 \%$ of NSCLC and control patients, respectively (Table V). The dominant GG genotype was identified in 22.1 and $29.4 \%$ of NSCLC patients and control individuals, respectively, while the recessive AA genotype was identified in 21.0 and $22.1 \%$ of NSCLC patients and control individuals, respectively. No significant difference was identified in the genotype $(\mathrm{P}=0.4351)$ frequency. The A allele was identified in 49.4 and $46.3 \%$ of NSCLC patients and control individuals, respectively, while the $\mathrm{G}$ allele was identified in 50.5 and $53.6 \%$ of NSCLC patients and control individuals, respectively. No significant difference was found in the allelic $(\mathrm{P}=0.2636)$ frequency.

IGF1R expression and survival data were available for 100 NSCLC patients. IGF1R expression was compared to the results of the genotype distribution in NSCLC patients using Kaplan-Meier analysis. Results showed no significant difference in genotype distribution (Fig. 2) or IGF1R 
Table V. Genotypic and allelic frequency of SNP rs2229765 in the IGFIR TK domain of NSCLC and control patients (ageand gender-matched).

\begin{tabular}{lccc}
\hline Frequency & $\begin{array}{c}\text { NSCLC patients } \\
(\mathrm{n}=95), \mathrm{n}(\%)\end{array}$ & $\begin{array}{c}\text { Control patients } \\
(\mathrm{n}=95), \mathrm{n}(\%)\end{array}$ & P-value \\
\hline Genotype & & & \\
AA & $20(21.0)$ & $21(22.1)$ & 0.4351 \\
GA & $54(56.8)$ & $46(48.4)$ & \\
GG & $21(22.1)$ & $28(29.4)$ & \\
Allele & & & \\
A & $94(49.4)$ & $88(46.3)$ & 0.2636 \\
G & $96(50.5)$ & $102(53.6)$ & \\
\hline
\end{tabular}

SNP, single-nucleotide polymorphisms; $I G F 1 R$, insulin-like growth factor 1 receptor; TK, tyrosine kinase; NSCLC, non-small cell lung cancer.

expression (Fig. 3A and B) in NSCLC patients. Analysis of genotype distribution in NSCLC patients showed that the P-value was 0.3564 while the P-value for trend was 0.1514 (Fig. 2). Analysis correlating IGF1R expression to genotype distribution in NSCLC patients showed that the $\mathrm{P}$-value was 0.3005 while the P-value for trend was 0.7099 in patients with heterozygous genotype (Fig. 3A), and that the $\mathrm{P}$-value was 0.1164 while the $\mathrm{P}$-value for trend was 0.0277 for patients with homozygous dominant and homozygous recessive genotype (Fig. 3B)

\section{Discussion}

A number of previous studies have identified factors that may influence sensitivity to IGF1R inhibitors. Kim et al (35) evaluated the anti-proliferation effect of figitumumab in gastric and hepatocellular cancer cell lines and showed that the level of N-linked glycosylated IGF1R/IR heterodimeric receptor is highly associated with sensitivity to anti-IGF1R antibody in cancer cells. Another study demonstrated that IGF1R TK inhibitors (TKIs) exhibited significant antitumor activity in NSCLC cells with wild-type EGFR and KRAS compared to those with mutations in these genes (36).

Although SNPs have been reported in IGF1R, there is limited knowledge regarding the frequency of gene aberrations in the TK domain of this gene. Patients who harbour point mutations and deletions within exons 18-21 of the EGFR TK domain are known to have increased sensitivity to EGFR TKIs. Therefore, the mutation status of the IGF1R TK domain may also influence the binding of IGFIR TKIs to this receptor and therefore influence patient response to targeted therapy.

The present study investigated the frequency of gene aberrations in the IGFIR TK domain in NSCLC patients and whether such changes may influence IGF1R expression or survival rate. Initially, 100 NSCLC patients were screened for the presence of mutations and or deletions in exons 16-21 of the IGFIR TK domain. No non-synonymous SNPs or deletions were detected in any of the 100 patients screened. A synonymous SNP (rs2229765) was identified in the coding region of exon 16. In order to strengthen the power of the study, a further 98 NSCLC patients were screened for the presence of the SNP (rs2229765) and the frequency was compared to control disease-free individuals $(\mathrm{n}=866)$. No significance was found in the genotype $(\mathrm{P}=0.5487)$ or the allelic $(\mathrm{P}=0.9082)$ frequency (Table IV).

When patients were age- and gender-matched, no significance was identified in the genotype $(\mathrm{P}=0.4351)$ or the allelic $(\mathrm{P}=0.2636)$ frequency (Table $\mathrm{V})$. The Kaplan-Meier survival analysis showed no significant survival advantage between the different genotypes in NSCLC patients (Fig. 2). There was also no significant difference when IGF1R expression was correlated to heterozygous genotype distribution in NSCLC patients. A significant difference for trend $(\mathrm{P}<0.05)$ was observed when IGF1R expression was correlated to combine the homozygous dominant and homozygous recessive genotype distribution in NSCLC patients (Fig. 3A and B).

The role of the SNP, rs2229765, has been examined in several diseases such as stroke breast cancer and type II diabetes. It is a synonymous mutation that encodes a change in the DNA sequence without altering the resultant protein sequence. These silent SNPs are presumed to be not significant but they may represent genetic markers for functional molecular alterations, as recent studies have revealed that through various mechanisms these synonymous SNPs may affect gene function and phenotype. Silent SNPs have been linked to $>40$ diseases that are a result of a genetic abnormality (37).

The possible role of this SNP has been investigated in numerous studies. According to FASTSNP, it is predicted that SNP rs2229765 may affect splicing regulation. It has been shown to affect the susceptibility to ischemic stroke in the Chinese population (38) and is associated with higher plasma concentrations of circulating IGF1R. In a study by Bonafè et al (39), polymorphic variants of the IGF1 response pathway genes, including IGF1R (G/A, codon 1013), phosphoinositol 3-kinase (T/C, $359 \mathrm{bp} ; \mathrm{A} / \mathrm{G}, 303 \mathrm{bp}$ ), insulin receptor substrate-1 (G/A, codon 972) and FOXO1A (T/C, 97,347 bp), were examined to observe whether they are involved in systemic IGF1 regulation and human longevity. It was found that subjects carrying at least an A allele at IGFIR have low free plasma IGF1 levels and live longer. A study performed in breast cancer identified that SNP rs2229765 had no association with breast cancer survival and that it appears to be a silent mutation (31). Therefore, thus far it has not been associated with any epidemiological traits. In another study, single SNP analysis revealed a significant association of SNP rs2229765 with percent and absolute mammographic density; increased numbers of the $\mathrm{G}$ allele increased the least squares means of mammographic density (40). The possible role of this polymorphism has also been examined in type II diabetes, which revealed no association with reduced birth weight, insulin sensitivity index or type II diabetes in a Danish population (41). These results also suggest that the rs2229765 polymorphism leads to a silent mutation.

A previous study investigated whether germline polymorphisms of the IGF1-pathway are associated with the response to cetuximab in wild-type KRAS drug-refractory metastatic colorectal cancer patients (mCRC) (28). Tissue samples from 130 drug-refractory mCRC patients enrolled in a phase II clinical trial of cetuximab monotherapy (IMC-0144) were used for the study. Analyses revealed that 5 IGF-pathway SNPs were 
significantly associated with progression-free survival and/or OS. Patients harbouring the IGF1 rs2946834 A/A genotype had a $50 \%$ overall response rate, while patients with the $\mathrm{A} / \mathrm{G}$ genotype had $0 \%$. This indicates that IGF1-pathway polymorphisms may predict cetuximab efficacy in wild-type KRAS mCRC patients.

Identifying functional polymorphisms in $I G F 1 R$ and its pathway could be used to select patients that would benefit from IGF1R-targeted therapy resulting in more accurate treatment for individuals with improved effectiveness and reduced toxicities. In the present cohort of 100 NSCLC patients, no non-synonymous SNPs were detected in the IGF1R TK domain. There was no significant association between SNP rs2229765 and IGFIR expression or patient survival. This data indicates that the IGFIR TK domain does not appear to be as susceptible to mutations as EGFR. Therefore, as opposed to $E G F R$, it will not be necessary to screen for mutations in $I G F 1 R$ to predict response to targeted therapy.

\section{Acknowledgements}

Genetic data on the control samples were generated by the International Schizophrenia Consortium.

\section{References}

1. Larsson O, Girnita A and Girnita L: Role of insulin-like growth factor 1 receptor signalling in cancer. Br J Cancer 92: 2097-2101, 2005.

2. Riedemann J and Macaulay VM: IGF1R signalling and its inhibition. Endocr Relat Cancer 13 (Suppl 1): S33-S43, 2006.

3. Cappuzzo F, Tallini G, Finocchiaro G, Wilson RS, Ligorio C, Giordano L, Toschi L, Incarbone M, Cavina R, Terracciano L, et al Insulin-like growth factor receptor 1 (IGF1R) expression and survival in surgically resected non-small-cell lung cancer (NSCLC) patients. Ann Oncol 21: 562-567, 2010.

4. Lee CY, Jeon JH, Kim HJ, Shin DH, Roh TW, Ahn CM and Chang YS: Clinical significance of insulin-like growth factor-1 receptor expression in stage I non-small-cell lung cancer: Immunohistochemical analysis. Korean J Intern Med 23: 116-120, 2008

5. Li R, Pourpak A and Morris SW: Inhibition of the insulin-like growth factor-1 receptor (IGF1R) tyrosine kinase as a novel cancer therapy approach. J Med Chem 52: 4981-5004, 2009.

6. Rochester MA, Riedemann J, Hellawell GO, Brewster SF and Macaulay VM: Silencing of the IGF1R gene enhances sensitivity to DNA-damaging agents in both PTEN wild-type and mutant human prostate cancer. Cancer Gene Ther 12: 90-100, 2005.

7. Gong Y, Yao E, Shen R, Goel A, Arcila M, Teruya-Feldstein J, Zakowski MF, Frankel S, Peifer M, Thomas RK, et al: High expression levels of total IGF-1R and sensitivity of NSCLC cells in vitro to an anti-IGF-1R antibody (R1507). PLoS One 4: e7273, 2009.

8. Vanamala J, Reddivari L, Radhakrishnan S and Tarver C: Resveratrol suppresses IGF-1 induced human colon cancer cell proliferation and elevates apoptosis via suppression of IGF-1R/Wnt and activation of p53 signaling pathways. BMC Cancer 10: 238, 2010.

9. Hellawell GO, Turner GD, Davies DR, Poulsom R, Brewster SF and Macaulay VM: Expression of the type 1 insulin-like growth factor receptor is up-regulated in primary prostate cancer and commonly persists in metastatic disease. Cancer Res 62: 2942-2950, 2002.

10. Samani AA, Yakar S, LeRoith D and Brodt P: The role of the IGF system in cancer growth and metastasis: Overview and recent insights. Endocr Rev 28: 20-47, 2007.

11. Yamamoto T, Oshima T, Yoshihara K, Nishi T, Arai H, Inui K, Kaneko T, Nozawa A, Adachi H, Rino Y, et al: Clinical significance of immunohistochemical expression of insulin-like growth factor-1 receptor and matrix metalloproteinase-7 in resected non-small cell lung cancer. Exp Ther Med 3: 797-802, 2012.
12. Nakagawa $M$, Uramoto $H$, Oka $S$, Chikaishi $Y$, Iwanami $T$, Shimokawa H, So T, Hanagiri T and Tanaka F: Clinical significance of IGF1R expression in non-small-cell lung cancer. Clin Lung Cancer 13: 136-142, 2012.

13. Zhao S, Qiu Z, He J, Li L, and Li W: Insulin-like growth factor receptor 1 (IGF1R) expression and survival in non-small cell lung cancer patients: A meta-analysis. Int J Clin Exp Pathol 7: 6694-6704, 2014.

14. Ludovini V, Bellezza G, Pistola L, Bianconi F, Di Carlo L, Sidoni A, Semeraro A, Del Sordo R, Tofanetti FR, Mameli MG, et al: High coexpression of both insulin-like growth factor receptor-1 (IGFR-1) and epidermal growth factor receptor (EGFR) is associated with shorter disease-free survival in resected non-small-cell lung cancer patients. Ann Oncol 20: 842-849, 2009.

15. Gately K, Forde L, Cuffe S, Cummins R, Kay EW, Feuerhake F and O'Byrne KJ: High coexpression of both EGFR and IGF1R correlates with poor patient prognosis in resected non-small-cell lung cancer. Clin Lung Cancer 15: 58-66, 2014.

16. Langer CJ, Novello S, Park K, Krzakowski M, Karp DD, Mok T, Benner RJ, Scranton JR, Olszanski AJ and Jassem J: Randomized, phase III trial of first-line figitumumab in combination with paclitaxel and carboplatin versus paclitaxel and carboplatin alone in patients with advanced non-small-cell lung cancer. J Clin Oncol 32: 2059-2066, 2014

17. Eberhard DA, Johnson BE, Amler LC, Goddard AD, Heldens SL, Herbst RS, Ince WL, Jänne PA, Januario T, Johnson DH, et al: Mutations in the epidermal growth factor receptor and in KRAS are predictive and prognostic indicators in patients with non-small-cell lung cancer treated with chemotherapy alone and in combination with erlotinib. J Clin Oncol 23: 5900-5909, 2005.

18. Lynch TJ, Bell DW, Sordella R, Gurubhagavatula S, Okimoto RA, Brannigan BW, Harris PL, Haserlat SM, Supko JG, Haluska FG, et al: Activating mutations in the epidermal growth factor receptor underlying responsiveness of non-small-cell lung cancer to gefitinib. N Engl J Med 350: 2129-2139, 2004.

19. Paez JG, Jänne PA, Lee JC, Tracy S, Greulich H, Gabriel S, Herman P, Kaye FJ, Lindeman N, Boggon TJ, et al: EGFR mutations in lung cancer: Correlation with clinical response to gefitinib therapy. Science 304: 1497-1500, 2004.

20. Gazdar AF, Shigematsu H, Herz J and Minna JD: Mutations and addiction to EGFR: The Achilles 'heal' of lung cancers? Trends Mol Med 10: 481-486, 2004.

21. Weinstein IB, Joe A and Felsher D: Oncogene addiction. Cancer Res 68: 3077-3080, 2008.

22. Al-Zahrani A, Sandhu MS, Luben RN, Thompson D, Baynes C, Pooley KA, Luccarini C, Munday H, Perkins B, Smith P, et al: IGF1 and IGFBP3 tagging polymorphisms are associated with circulating levels of IGF1, IGFBP3 and risk of breast cancer. Hum Mol Genet 15: 1-10, 2006.

23. Feik E, Baierl A, Hieger B, Führlinger G, Pentz A, Stättner S, Weiss W, Pulgram T, Leeb G, Mach K, et al: Association of IGF1 and IGFBP3 polymorphisms with colorectal polyps and colorectal cancer risk. Cancer Causes Control 21: 91-97, 2010.

24. Verheus M, McKay JD, Kaaks R, Canzian F, Biessy C, Johansson M, Grobbee DE, Peeters PH and van Gils CH: Common genetic variation in the IGF-1 gene, serum IGF-I levels and breast density. Breast Cancer Res Treat 112: 109-122, 2008.

25. Lönn S, Rothman N, Shapiro WR, Fine HA, Selker RG, Black PM, Loeffler JS, Hutchinson AA and Inskip PD: Genetic variation in insulin-like growth factors and brain tumor risk. Neuro Oncol 10: 553-559, 2008.

26. de Alencar SA and Lopes JCD: A comprehensive in silico analysis of the functional and structural impact of SNPs in the IGF1R gene. J Biomed Biotechnol 2010: 715139, 2010.

27. MacDonald K, Porter GA, Guernsey DL, Zhao R and Casson AG: A polymorphic variant of the insulin-like growth factor type I receptor gene modifies risk of obesity for esophageal adenocarcinoma. Cancer Epidemiol 33: 37-40, 2009

28. Li HR, Chen YS, Shao H, Han LL and Zhang XE: Association between polymorphisms of insulin-like growth factor receptor gene and susceptibility to non-small-cell lung cancer in Fujian Chinese. Zhonghua Yi Xue Yi Chuan Xue Za Zhi 29: 300-305, 2012 (In Chinese).

29. Chen Y, Shao H, Li H, Han L and Zhang X: Relationship of insulin-like growth factor receptor single nucleotide polymorphism (SNP) with platinum-based chemotherapy outcomes in advanced non-small cell lung cancer. Zhongguo Fei Ai Za Zhi 15: 65-71, 2012 (In Chinese). 
30. Winder T, Zhang W, Yang D, Ning Y, Bohanes P, Gerger A, Wilson PM, Pohl A, Mauro DJ, Langer C, et al: Germline polymorphisms in genes involved in the IGF1 pathway predict efficacy of cetuximab in wild-type KRAS mCRC patients. Clin Cancer Res 16: 5591-5602, 2010.

31. Deming SL, Ren Z, Wen W, Shu XO, Cai Q, Gao YT and Zheng W: Genetic variation in IGF1, IGF-1R, IGFALS, and IGFBP3 in breast cancer survival among Chinese women: A report from the Shanghai Breast Cancer Study. Breast Cancer Res Treat 104: 309-319, 2007.

32. Reinmuth N, Kloos S, Warth A, Risch A, Muley T, Hoffmann H, Thomas $\mathrm{M}$ and Meister M: Insulin-like growth factor 1 pathway mutations and protein expression in resected non-small cell lung cancer. Hum Pathol 45: 1162-1168, 2014.

33. Mountain CF: The international system for staging lung cancer. Semin Surg Oncol 18: 106-115, 2000

34. Purcell SM, Wray NR, Stone JL, Visscher PM, O'Donovan MC, Sullivan PF and Sklar P; International Schizophrenia Consortium: Common polygenic variation contributes to risk of schizophrenia and bipolar disorder. Nature 460: 748-752, 2009.

35. Kim JG, Kang MJ, Yoon YK, Kim HP, Park J, Song SH, Han SW, Park JW, Kang GH and Kang KW, et al: Heterodimerization of glycosylated insulin-like growth factor-1 receptors and insulin receptors in cancer cells sensitive to anti-IGF1R antibody. PLoS One 7: e33322, 2012.

36. Kim WY, Prudkin L, Feng L, Kim ES, Hennessy B, Lee JS Lee JJ, Glisson B, Lippman SM, Wistuba II, et al: Epidermal growth factor receptor and K-Ras mutations and resistance of lung cancer to insulin-like growth factor 1 receptor tyrosine kinase inhibitors. Cancer 118: 3993-4003, 2012.
37. Hunt R, Sauna ZE, Ambudkar SV, Gottesman MM and Kimchi-Sarfaty C: Silent (synonymous) SNPs: Should we care about them? Methods Mol Biol 578: 23-39, 2009.

38. Cheng J, Liu J, Li X, Peng J, Han S, Zhang R, Xu Y and Nie S: Insulin-like growth factor-1 receptor polymorphism and ischemic stroke: A case-control study in Chinese population. Acta Neurol Scand 118: 333-338, 2008.

39. Bonafè M, Barbieri M, Marchegiani F, Olivieri F, Ragno E, Giampieri C, Mugianesi E, Centurelli M, Franceschi C and Paolisso G: Polymorphic variants of insulin-like growth factor I (IGF-I) receptor and phosphoinositide 3-kinase genes affect IGF-I plasma levels and human longevity: Cues for an evolutionarily conserved mechanism of life span control. J Clin Endocrinol Metab 88: 3299-3304, 2003.

40. Diorio C, Brisson J, Bérubé S and Pollak M: Genetic polymorphisms involved in insulin-like growth factor (IGF) pathway in relation to mammographic breast density and IGF levels. Cancer Epidemiol Biomarkers Prev 17: 880-888, 2008

41. Rasmussen SK, Lautier C, Hansen L, Echwald SM, Hansen T, Ekstrøm CT, Urhammer SA, Borch-Johnsen K, Grigorescu F, Smith RJ, et al: Studies of the variability of the genes encoding the insulin-like growth factor I receptor and its ligand in relation to type 2 diabetes mellitus. J Clin Endocrinol Metab 85: 1606-1610, 2000. 